\title{
Pulmonary Munchausen's syndrome
}

\author{
A. BUSH* \\ M.A., M.R.C.P. \\ ·J. V. COLLINS \\ M.D., F.R.C.P.
}

\author{
Brompton Hospital, Fulham Road, London SW3
}

\section{Summary}

The scarred abdomen of the patient with Munchausen's syndrome is a familiar physical sign. We report on a man with Munchausen's syndrome who had not multiple laparotomies but two thoracotomies.

\section{Introduction}

Subsequent to the first description of Munchausen's syndrome 30 years ago (Asher, 1951), other bizarre accounts have been published (Pallis and Bamji, 1979; Burman and Stevens, 1977). We report a further such case.

\section{Case report}

Mr E.R.H., a 25-year-old alleged South African, was referred to the Brompton Hospital. He said that he had been fit until nine months previously when he developed breathlessness and a cough productive of purulent sputum. He had been treated with antibiotics with no improvement.

Three months later he claimed that he had haemoptyses of cupfuls of blood alone or mixed with sputum. He had bronchoscopy and bronchograms and was told that he had an infection. Haemoptysis continued despite further courses of antibiotics and he was submitted to thoracotomy and resection of part of the left lung. Postoperatively he said he had further haemoptyses, his chest was reopened and further parts of his left lung were removed. Thereafter he remained unwell and came to the United Kingdom on holiday. His cough, purulent sputum and copious haemoptyses returned ten days before admission. He also said he had had a bilateral surgical lumbar sympathectomy after badly injuring his legs in a road traffic accident.

Examination revealed a fit man smelling of alcohol. The only physical signs were a left thoracotomy scar and bilateral lower abdominal scars. He was never observed actually coughing up blood, although he showed us sputum pots containing blood.

A full range of routine investigations was normal.

* Present address: Renal Unit, St Mary's Hospital, London W2.
Chest X-ray and lateral tomograms showed a possible mass behind the left hilum. Bronchoscopy and bilateral bronchograms showed that the left upper lobe and lingula had been removed, but otherwise no abnormality was found. A computed tomographic (CT) scan of the chest suggested only post-surgical scarring in the left hemithorax. Screening tests for possible factors predisposing to bronchiectasis were negative.

An otolaryngologist found no upper airways cause of bleeding. The patient had further haemoptyses but bronchoscopy again failed to show any blood or endobronchial abnormality.

Further inquiries revealed that he was unknown af his alleged place of work or at the South Africa Embassy. The real sequence of events was as follow: he first presented in South Africa in June 1980 with $¥$ claim of recurrent large haemoptyses. Bronchoscopy was said to show blood originating from the lingula. Bronchography showed slight cylindrical widening of the lingula bronchi. Thoracotomy and removal of the lingula was carried out at his insistence because he said he was so disturbed by these large haemoptyses.

Macroscopically a mild degree of bronchiectasis was demonstrated and confirmed histologically. Careful dissection revealed no source of haemoptysis. Unfortunately the radiographs are lost, having been given to him when he left South Africa. His creditors tried to prevent him leaving until he had settled large debts. On arrival in the U.K. he went to another hospital, again claiming he was having large haemoptyses. Bronchoscopy was thought to show a small broncho-pleural fistula and at his importuning a second thoracotomy was performed.

At operation the left upper lobe was removed to gain access to the fistula. The excised specimen was essentially normal and he discharged himself after the operation, leaving his bill unpaid. Months later he presented to us with further alleged haemoptyses.

Psychiatrists thought him to be an immature. personality, and a compulsive habitual liar. He has repeatedly accumulated large debts and has been disowned by his family. We traced further admis- 
sions to London hospitals and he will certainly appear again. He was recently in prison for allegeg misuse of credit cards.

\section{Discussion}

Munchausen's syndrome (Asher, 1951) has been divided into three types-the acute abdominal ('laparotomophilia migrans'), the bleeders (colloquially 'haemoptysis and haematemesis merchants') and the neurological ('neurologica diabolica').

This man shows many features of the original account-pathological lying, many admissions to hospital, ready submission to multiple procedures, self-discharge from hospital, history of psychopathology and criminal behaviour. Abdominal Munchausens characteristically have multiple laparotomieswe believe this patient to be a rare "haemoptysis merchant' who has had two thoracotomies.

\section{References}

ASHER, R . (1951) Munchausen's syndrome. Lancet, i, 339.

BURMAN, D . \& STEVENS, D . (1977) Munchausen's family (Letter). Lancet, if, 456.

Pallis, C . A . \& BAmu, A . N . (1979) Mcllroy was here. Or was he? British Medical Journal, i, 973. 